Article

\title{
Precipitation during $\gamma-\varepsilon$ Phase Transformation in Biomedical Co-Cr-Mo Alloys Fabricated by Electron Beam Melting
}

\author{
Kosuke Ueki ${ }^{1, *}$, Motoka Kasamatsu ${ }^{2}$, Kyosuke Ueda $^{2}$, Yuichiro Koizumi ${ }^{3}$, Daixiu Wei ${ }^{4}$, \\ Akihiko Chiba ${ }^{4}$ and Takayuki Narushima ${ }^{2,5}$ (D) \\ 1 Department of Mechanical Engineering, Faculty of Science and Engineering, Kindai University, 3-4-1, \\ Kowakae, Higashiosaka 577-8502, Japan \\ 2 Department of Materials Processing, Graduate School of Engineering, Tohoku University, 6-6-02, Aza-Aoba, \\ Aramaki, Aoba-ku, Sendai 980-8579, Japan; motoka_kasamatsu@jsw.co.jp (M.K.); \\ ueda@material.tohoku.ac.jp (K.U.); narut@material.tohoku.ac.jp (T.N.) \\ 3 Division of Materials Science and Engineering, Graduate School of Engineering, Osaka University, 2-1, \\ Yamada-Oka, Suita, Osaka 565-0871, Japan; ykoizumi@mat.eng.osaka-u.ac.jp \\ 4 Institute for Materials Research, Tohoku University, 2-1-1, Katahira, Aoba-ku, Sendai 980-8577, Japan; \\ wei1987xiu@imr.tohoku.ac.jp (D.W.); a.chiba@imr.tohoku.ac.jp (A.C.) \\ 5 Research Center for Structural Materials, National Institute for Materials Science (NIMS), 1-2-1 Sengen, \\ Tsukuba, Ibaraki 305-0047, Japan \\ * Correspondence: ueki@mech.kindai.ac.jp; Tel.: +81-6-4307-3474
}

Received: 25 November 2019; Accepted: 25 December 2019; Published: 2 January 2020

Abstract: We studied the precipitates that were induced during $\gamma-\varepsilon$ phase transformation in biomedical Co-28Cr-6Mo (mass\%) alloys that were fabricated by electron beam melting with carbon contents of 0.184 and 0.018 mass $\%$. In the high-C as-built alloy, $\mathrm{M}_{23} \mathrm{X}_{6}$-type, $\pi$-phase $\left(\mathrm{M}_{3} \mathrm{~T}_{2} \mathrm{X}\right.$-type), and $\eta$-phase $\left(\mathrm{M}_{6} \mathrm{X}-\mathrm{M}_{12} \mathrm{X}\right.$-type) precipitates were observed ( $\mathrm{M}$ and $\mathrm{T}$ : metallic elements, $\mathrm{X}: \mathrm{C}$ and/or $\mathrm{N}$ ). $\sigma$-phase $(\mathrm{Co}(\mathrm{Cr}, \mathrm{Mo})), \pi$-phase, and $\mathrm{Co}_{3} \mathrm{Mo}_{2} \mathrm{Si}$-type precipitates were observed in the low-C as-built alloy. This is the first report that shows the presence and chemical composition of this precipitate, as the $\mathrm{Co}_{3} \mathrm{Mo}_{2} \mathrm{Si}$-type precipitate has not been detected in biomedical $\mathrm{Co}-\mathrm{Cr}-\mathrm{Mo}$ alloys before. After aging in the $\varepsilon$-phase stability region, the high-C and low-C alloys both contained a single $\varepsilon$-phase matrix, and the amount of $\pi$-phase precipitates increased. Conversely, the amount of $\pi$-phase precipitates in both alloys decreased when a reverse transformation treatment was applied in the $\gamma$-phase stability region after aging. In the low-C alloy, the amount of $\mathrm{Co}_{3} \mathrm{Mo}_{2} \mathrm{Si}$-type precipitates increased after reverse transformation treatment. These results indicate that the dissolution of $\pi$-phase precipitates and the formation of $\mathrm{CO}_{3} \mathrm{Mo}_{2} \mathrm{Si}$-type precipitates during reverse transformation promote the formation of fine $\gamma$-phase grains at the precipitate/ $\varepsilon$-phase matrix interface, because the formation and dissolution of these precipitates affect the $\gamma$-phase stability of the matrix.

Keywords: Co-Cr-Mo alloy; additive manufacturing; heat treatment; reverse transformation treatment

\section{Introduction}

The Co-28Cr-6Mo (mass\%, CoCrMo) alloys have been used in biomedical implant devices, such as the sliding parts of artificial joints, spinal fixation rods, and dental denture bases, due to their of their excellent strengths, wear resistance, and corrosion resistance [1-5]. CoCrMo alloys exhibit low stacking fault energy (SFE); therefore, the $\varepsilon$-phase (HCP structure) is stable at room temperature, resulting in poor workability [6]. The $\gamma$-phase (FCC structure) can be stabilized, even at room temperature by adding $\mathrm{C}$ and/or $\mathrm{N}$ to a CoCrMo alloy $[7,8]$. However, a martensitic transformation, i.e., from $\gamma$ to $\varepsilon$, occurs during plastic deformation. 
The fabrication of CoCrMo alloy products has been attempted by additive manufacturing (AM) to solve this problem $[9,10]$. In AM, the products can be fabricated without being affected by the workability of the alloy; moreover, medical devices can be tailor-made for each patient. There are two types of AM processes: selective laser melting (SLM) and electron beam melting (EBM). The microstructure, mechanical properties, and corrosive properties of CoCrMo alloys that were fabricated by SLM and EBM have been investigated [10-19].

In this study, we focused on EBM, which is an AM technique [9]. In the EBM process, an alloy powder is preheated to $50-80 \%$ of its melting point by a fast scanning electron beam before being melted. This process facilitates the melting of the alloy powder, suppresses the formation of pores and cracks, and reduces the residual stress of the final product [9,12-14]. A pre-heating temperature of approximately $1023 \mathrm{~K}$ is required for a CoCrMo alloy in the EBM process, which is lower than its $\gamma-\varepsilon$ martensitic transformation temperature ( 1173 K) [14]. Therefore, the $\gamma$-phase that is formed by solidification during rapid cooling following electron-beam irradiation is transformed into the $\varepsilon$-phase during the pre-heating process. In addition, the thermal history depends on the part of the product, e.g., the exposure time of the pre-heating process for the bottom part is longer than that for the top part. In other words, the $\gamma \rightarrow \varepsilon$ martensitic transformation occurs during the pre-heating process to form an inhomogeneous structure with different $\gamma / \varepsilon$ phase fractions, depending on the location in the product [16-19].

A reverse transformation treatment with $\gamma-\varepsilon$ martensitic transformation has been reported to homogenize the structure and refine the grains of EBM products [19-22]. In this process, an alloy is heat treated at $1023 \mathrm{~K}$ for $43.2 \mathrm{ks}$ (aging), which results in a single $\varepsilon$-phase structure. Subsequently, the alloy is heat treated at $1273 \mathrm{~K}$ for $0.6 \mathrm{ks}$ (reverse transformation treatment) to simultaneously yield a single $\gamma$-phase structure and grain refinement. The eutectoid structure of the $\varepsilon$-phase and the $\mathrm{Cr}_{2} \mathrm{~N}$ that formed during aging become $\gamma$-phase nucleation sites, and the fine $\gamma$-phase grains are formed through the $\varepsilon+\mathrm{Cr}_{2} \mathrm{~N} \rightarrow \gamma$ reaction during the reverse transformation [20]. However, $\mathrm{Cr}_{2} \mathrm{~N}$-type precipitates have not been detected in CoCrMo alloys that were fabricated by EBM [17], and the relationship between the precipitates and grain refinement during reverse transformation has not been clarified.

Our group previously established an analysis method for the precipitates of CoCrMo alloys [23-28]. Elucidating the role of the precipitates in grain refinement through reverse transformation treatment in CoCrMo alloys fabricated by EBM is the purpose of this study.

\section{Materials and Methods}

\subsection{Specimens}

Two types of CoCrMo alloy bar with carbon contents of 0.184 and 0.018 mass $\%$ were fabricated by EBM and they were used as base materials, hereinafter referred to as high-C and low-C alloys, respectively. Table 1 lists the chemical compositions of the two alloys. The EBM process was conducted under the same conditions as in our previous study [17]. The dimensions of the as-built high-C and low-C alloy rods were $\phi 18 \mathrm{~mm} \times 160 \mathrm{~mm}$ and $\phi 18 \mathrm{~mm} \times 140 \mathrm{~mm}$, respectively. Three parts of each rod, namely the top, center, and bottom were tested in this study, as shown in Figure 1.

Table 1. Chemical compositions of Co-Cr-Mo alloys used in this study (mass\%).

\begin{tabular}{cccccccccccc}
\hline Alloy & Co & Cr & Mo & Ni & Fe & Si & Mn & C & N & O & S \\
\hline $\begin{array}{c}\text { high-C } \\
\left(\begin{array}{c}\text { mass } \%) \\
\text { low-C }\end{array}\right.\end{array}$ & Bal. & 28.1 & 6.12 & 0.13 & 0.23 & 0.35 & 0.42 & 0.184 & 0.114 & 0.0058 & 0.0024 \\
$($ mass $\%)$ & Bal. & 27.5 & 6.01 & 0.01 & 0.02 & 0.6 & 0.41 & 0.018 & 0.101 & 0.0076 & 0.0006 \\
\hline
\end{tabular}




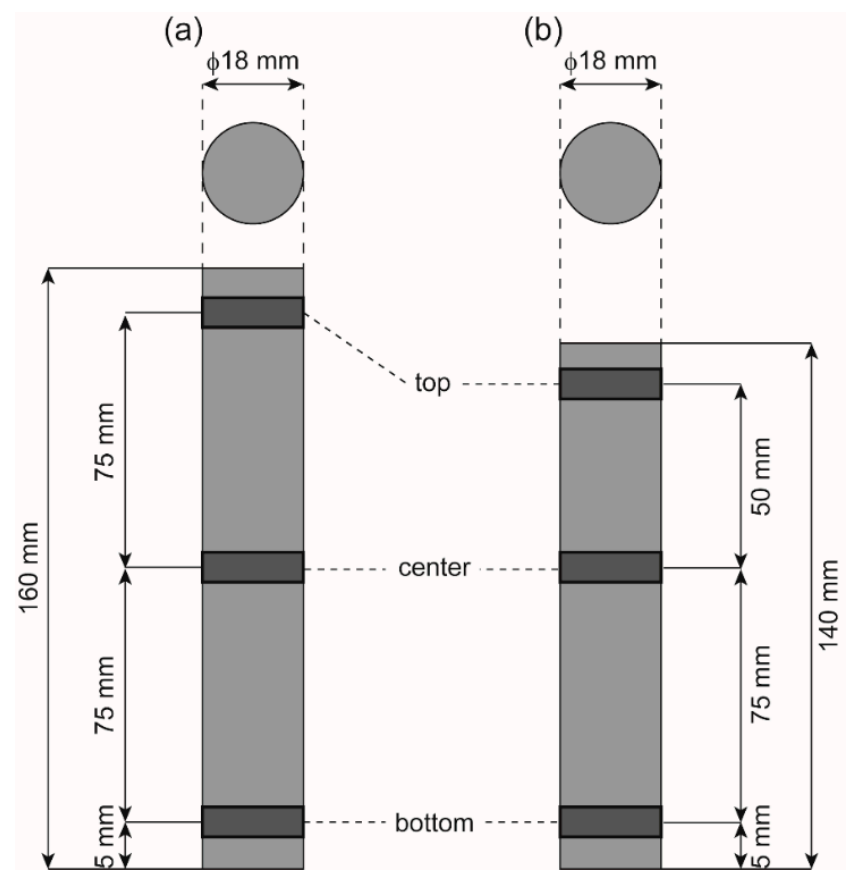

Figure 1. Schematics of as-built bar specimens used in this study: (a) high-C and (b) low-C alloys.

\subsection{Heat Treatment}

The as-built alloys were aged at $1023 \mathrm{~K}$ ( $\varepsilon$-phase stability region) for $43.2 \mathrm{ks}$ (aged alloys). Subsequently, the aged alloys were heat treated at $1273 \mathrm{~K}$ ( $\gamma$-phase stability region) for $0.6 \mathrm{ks}$ (reversely transformed alloys). The reverse transformation treatment of some of the low-C-aged samples was interrupted at 76, 78, 80, and $90 \mathrm{~s}$ to analyze the precipitation and phase transformation behavior during the reverse transformation treatment; these alloy specimens are referred to as middle-RT 76-90 alloys. Figure 2 shows the heat treatment process that was used in this study. The coin-shaped top, center, and bottom parts were cut from the high-C and low-C as-built alloy bars, and then further divided into three to secure the required number of specimens. The alloys were sealed inside $\mathrm{SiO}_{2}$ ampoules under an Ar atmosphere at a pressure of approximately $0.02-0.03 \mathrm{MPa}$ to avoid decarburization and/or denitrization during heat treatment [24,25]. The $\mathrm{SiO}_{2}$ ampoules containing the specimens were placed in an electric-resistance muffle furnace heated to the desired temperature. The alloys were simultaneously water-quenched by breaking the $\mathrm{SiO}_{2}$ ampoules after heat treatment.

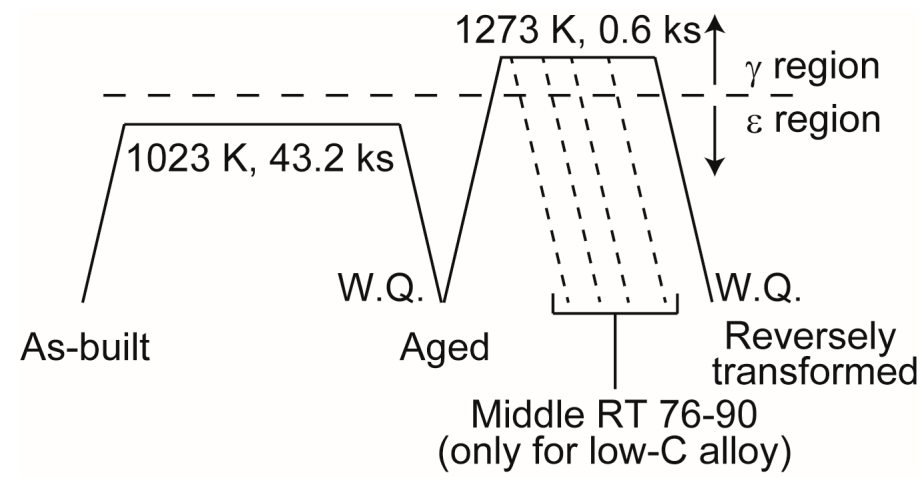

Figure 2. Schematic of the heat treatment process that was used in this study.

\subsection{Microstructure Observation and Analysis}

The microstructures of the alloys were observed by scanning electron microscopy-backscattered electron imaging (SEM-BSE, Philips XL30FEG, Royal Philips, Amsterdam, The Netherlands) and 
electron backscattering diffraction (EBSD, OIM Analysis, AMETEK Inc., Berwyn, PA, USA). The $\varepsilon$-phase fraction of the matrix was calculated from the EBSD phase maps of the alloys. Calculating the areal percentage of the precipitation region from the SEM-BSE images using the Image J image-analyzing software (Version 1.51, NHI, Bethesda, MD, USA) determined the amount of precipitates. In addition, transmission electron microscopy-energy dispersive X-ray spectrometry (TEM-EDX, JEM-2100, JEOL Ltd. Tokyo, Japan) analyzed the chemical compositions of the precipitates.

The precipitate phases were analyzed. The precipitates were electrolytically extracted at $1 \mathrm{~V}$ for $10.8 \mathrm{ks}$ in a $10 \% \mathrm{H}_{2} \mathrm{SO}_{4}-90 \% \mathrm{CH}_{3} \mathrm{OH}$ (vol.) solution. The precipitates that were electrolytically extracted from the alloys were collected as residue after filtering the electrolyte and then analyzed by X-ray diffraction (XRD, D8 Advance, Bruker AXS K.K., Karlsruhe, Germany) [23-28].

The microstructure of each specimen was analyzed at least three times.

\section{Results}

\subsection{Phase Transformation Behavior during Aging and Reverse Transformation Treatment}

Figure 3 shows the $\varepsilon$-phase fraction and grain size of the as-built, aged, and reversely transformed alloys. In the high-C alloy, the $\varepsilon$-phase fraction increases after aging and then decreases after the reverse transformation treatment. In the low-C alloy, no significant change in the $\varepsilon$-phase fraction was observed upon aging, but the $\varepsilon$-phase fraction decreased upon reverse transformation treatment, as was observed for the high-C alloy. The $\varepsilon$-phase fraction is independent of the height of the alloy specimens except for the high-C as-built alloy specimen. The grains at the top parts of the as-built alloys are smaller than those at the bottom. The aged and as-built alloys have largely similar grain sizes. The reverse transformation treatment helped to refine the grains and reduce the grain size dependency on part location.

(a) High-C

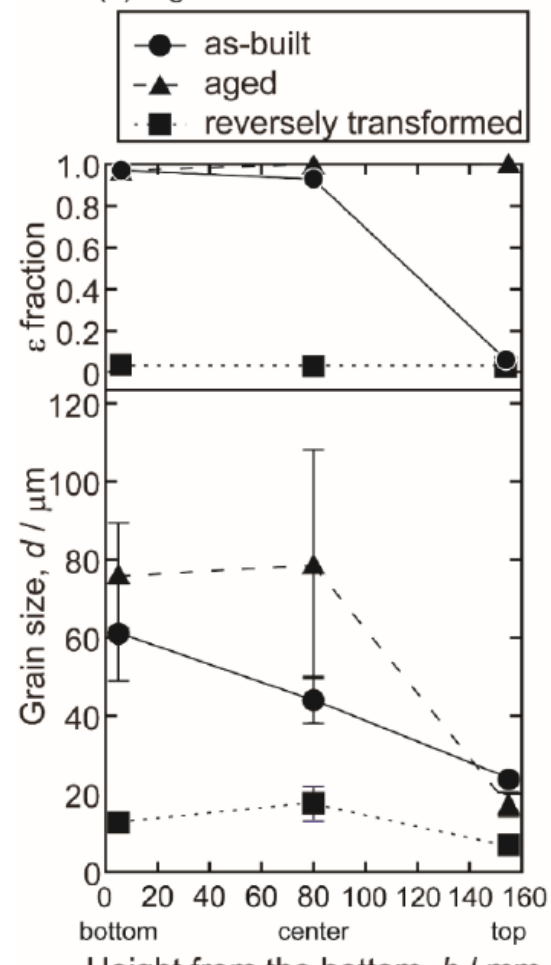

(b) Low-C

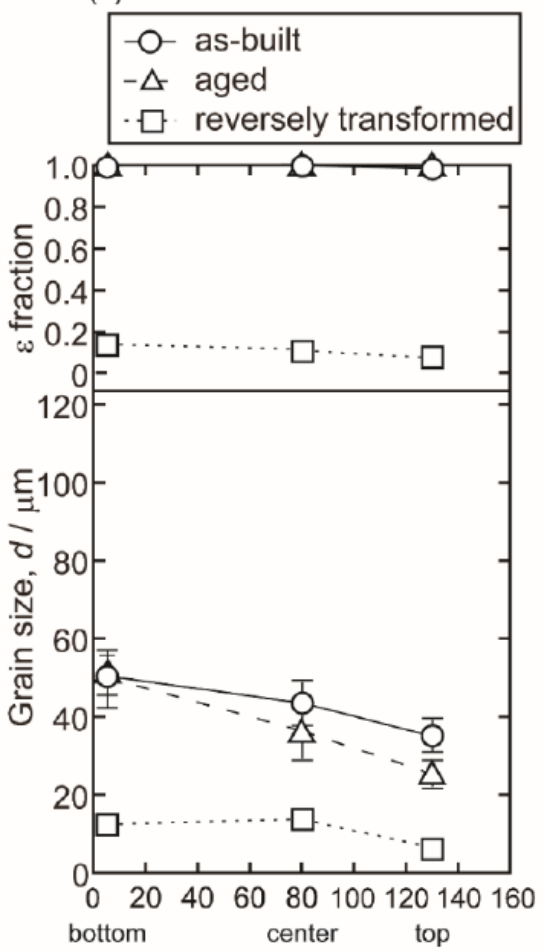

Height from the bottom, $h / \mathrm{mm}$

Figure 3. $\varepsilon$-phase fraction and average grain size at the top, center, and bottom parts of the as-built, aged, and reversely transformed specimens of (a) high-C and (b) low-C alloys. 


\subsection{Precipitation during Aging and Reverse Transformation Treatment}

Figure 4 shows the SEM-BSE images of the high-C as-built alloy. Three types of blocky precipitate (black, white, and gray) can be observed in all parts. These precipitates were also observed after aging and reverse transformation treatment. The precipitates are formed at both the grain boundaries and in the intragrain regions. Figure 5 shows the SEM-BSE images of the as-built, aged, and reversely transformed low-C alloys. In the low-C as-built and aged alloys, blocky white, blocky gray, and needle-shaped black precipitates can be observed, whereas only two types of precipitate (blocky white and blocky gray precipitates) are observed in the low-C reversely transformed alloy.
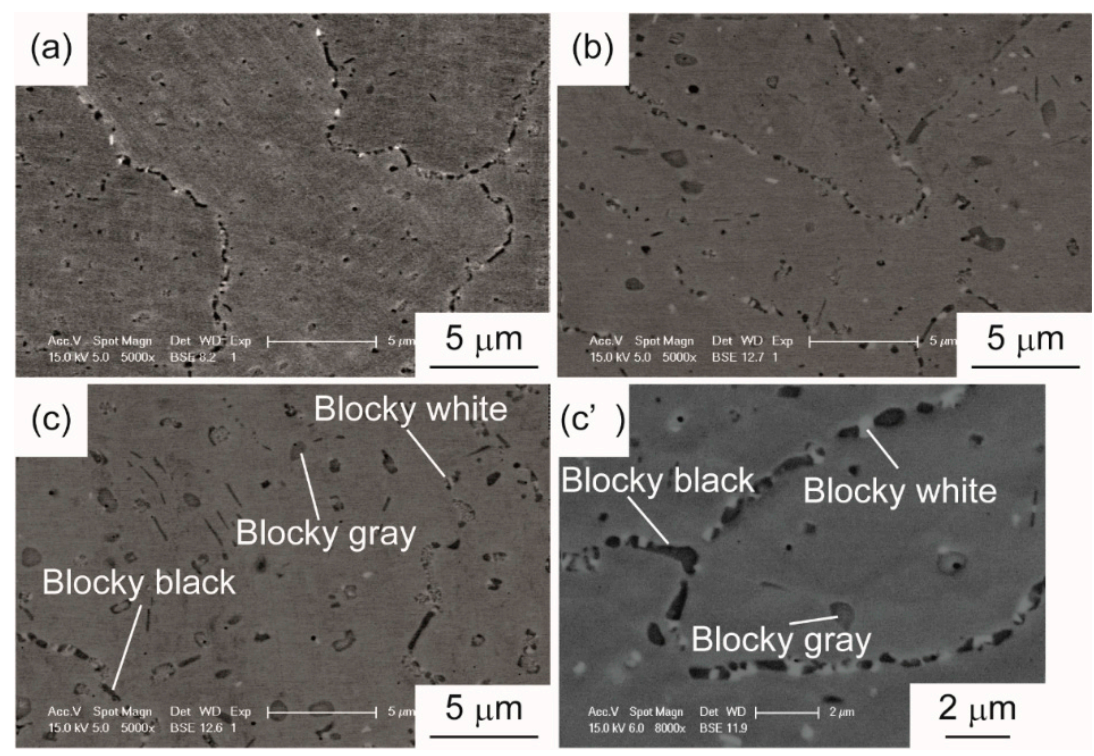

Figure 4. Scanning electron microscopy-backscattered electron imaging (SEM-BSE) images of the (a) top part, (b) center part, and $\left(\mathbf{c}, \mathbf{c}^{\prime}\right)$ bottom part of the high-C as-built alloy; ( $\left.\mathbf{c}^{\prime}\right)$ is a magnified image of $(\mathbf{c})$.
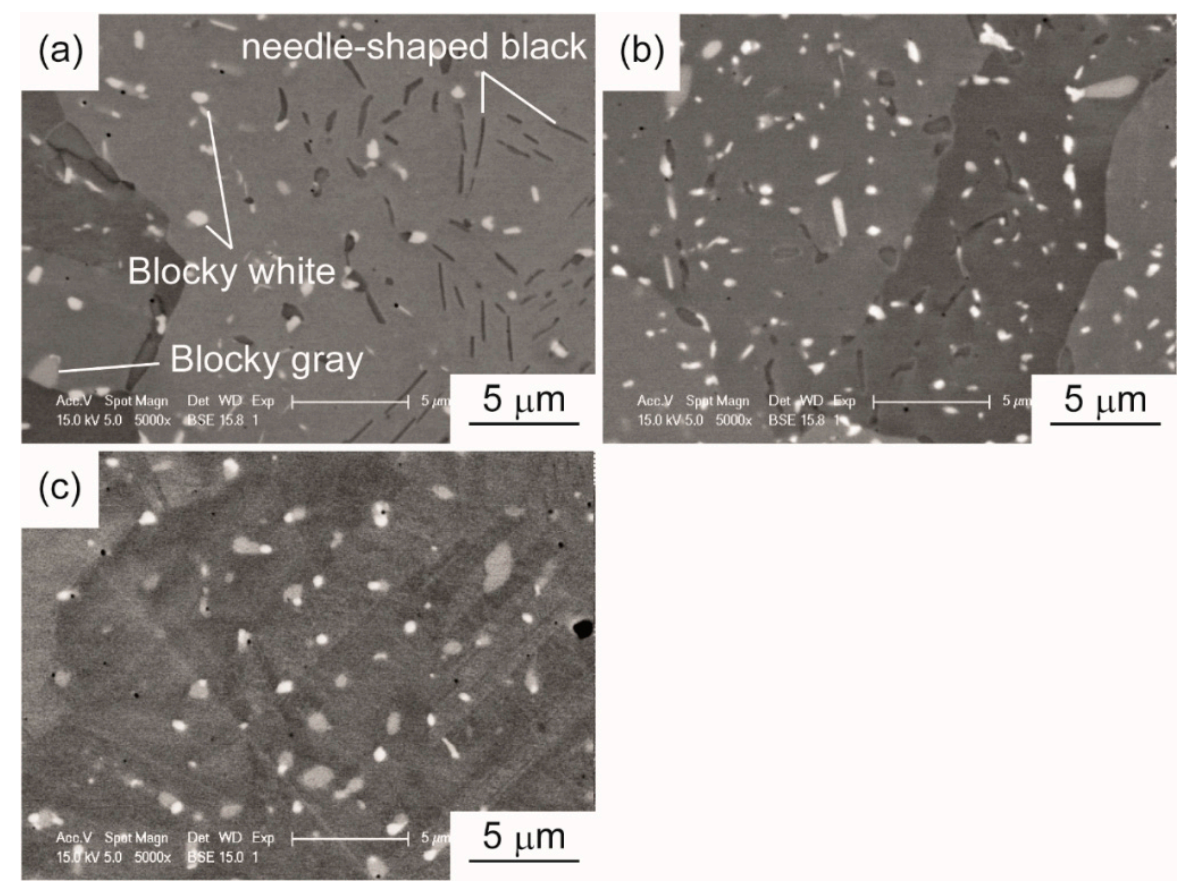

Figure 5. SEM-BSE images of the (a) as-built, (b) aged, and (c) reversely transformed specimens of the low-C alloy. 
Figure 6 shows the XRD patterns of the precipitates that were electrolytically extracted from the high-C alloys. Peaks that are associated with $\mathrm{M}_{23} \mathrm{X}_{6}$-type, $\pi$-phase, and $\eta$-phase precipitates can be detected from all parts of the high-C alloy. The aging and reverse transformation treatment did not affect the phases of the precipitates. In Figure $6 \mathrm{a}$, the peaks corresponding to the -phase matrix were detected. We conclude that part of the matrix peeled off with the precipitates during electrolytic extraction. Figure 7 shows the XRD patterns of the precipitates that were electrolytically extracted from the low-C alloys. In the low-C as-built and aged alloys, $\mathrm{Co}_{3} \mathrm{Mo}_{2} \mathrm{Si}$-type, $\sigma$-phase (intermetallic phase), and $\pi$-phase precipitates can be detected, whereas the $\mathrm{Co}_{3} \mathrm{Mo}_{2} \mathrm{Si}$-type and $\sigma$-phase precipitates are detected in the low-C reversely transformed alloy. Among the precipitates, the $\mathrm{Co}_{3} \mathrm{Mo}_{2} \mathrm{Si}$-type precipitate that was detected in the low-C alloy has not been reported in previous studies on biomedical CoCrMo alloys.
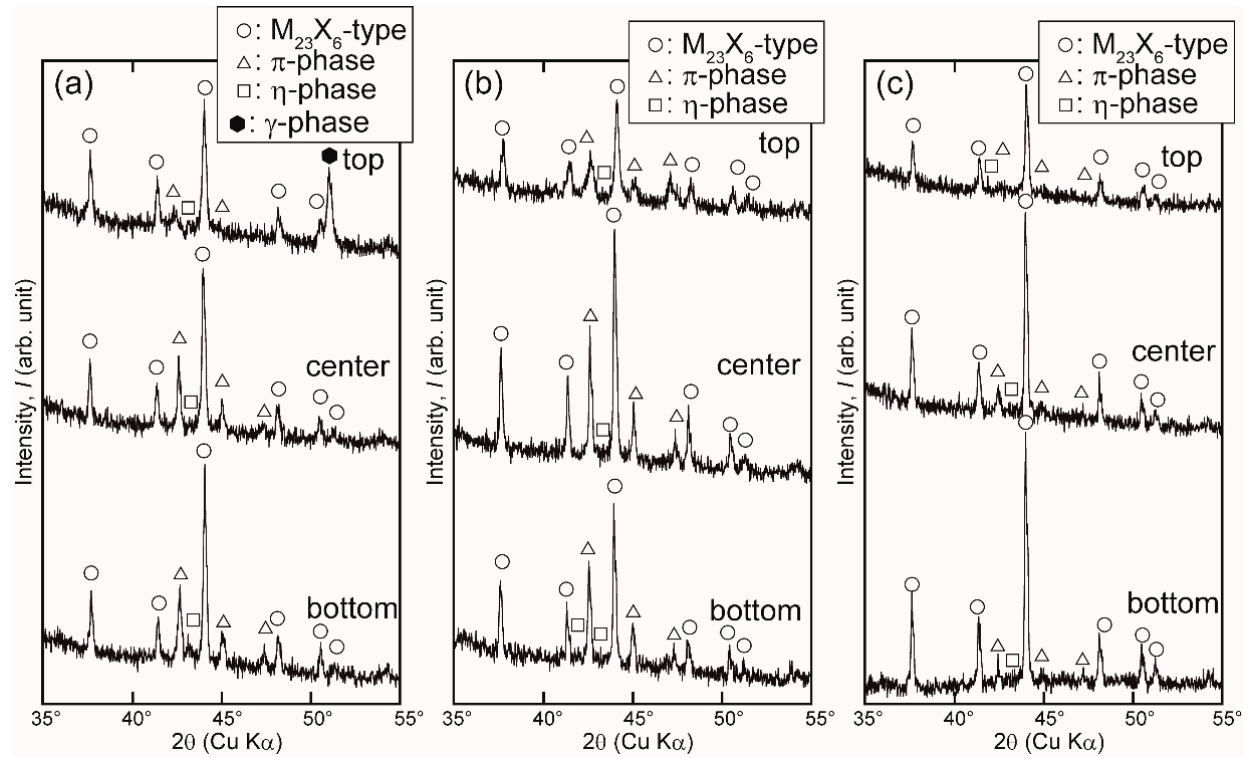

Figure 6. X-ray diffraction (XRD) patterns of the precipitates electrolytically extracted from the (a) as-built, (b) aged, and (c) reversely transformed specimens of the high-C alloy.
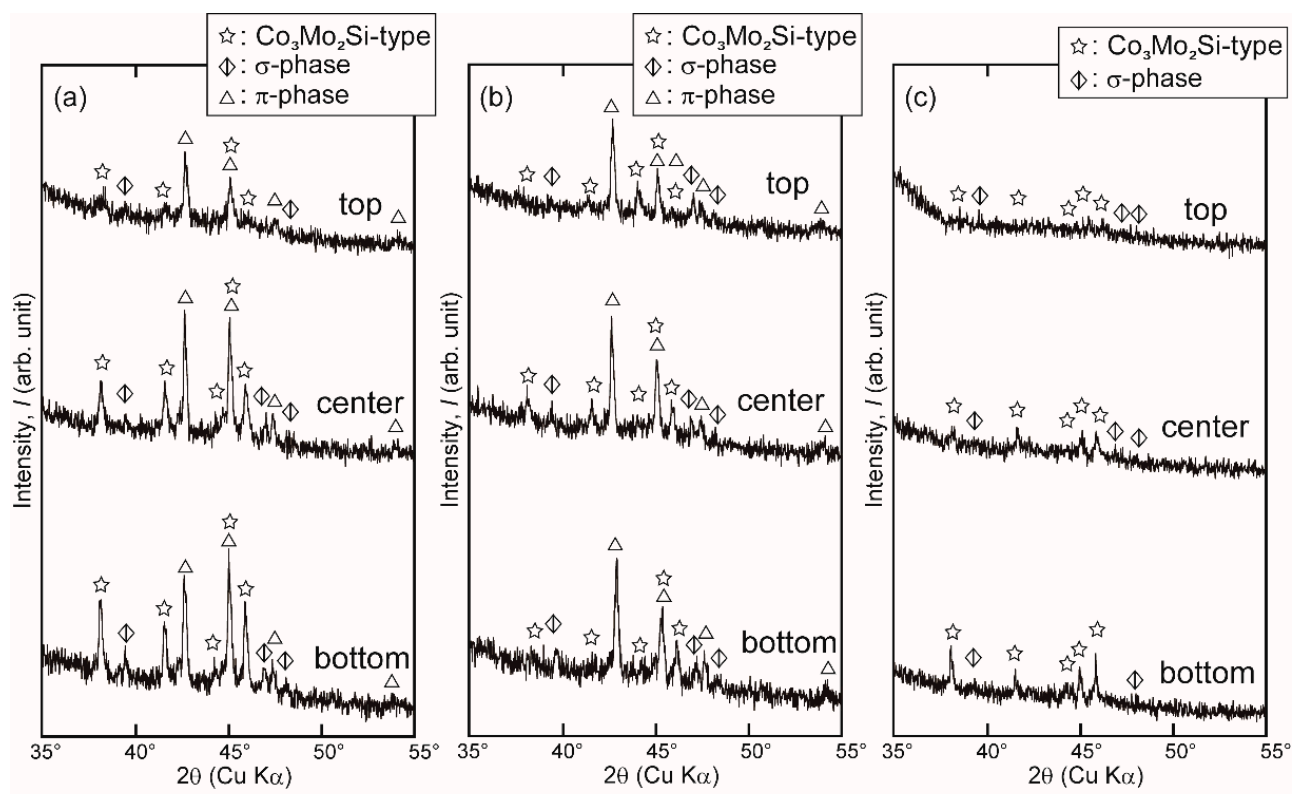

Figure 7. XRD patterns of the precipitates electrolytically extracted from the (a) as-built, (b) aged, and (c) reversely transformed specimens of the low-C alloy. 


\section{Discussion}

\subsection{Effect of Carbon Content on the Phase and Amount of Precipitates}

As shown in Figure 3, the difference in the behavior of the $\varepsilon$-phase fraction between the high-C and low-C alloys during aging is due to the difference in the initial $\varepsilon$-phase fractions of the two alloys. In the CoCrMo alloy, carbon acts as a $\gamma$-phase-stabilizing element [8]. In addition, the $\gamma$-phase formed during does not fully transform into an $\varepsilon$-phase during the pre-heating process, since the top part is less affected by pre-heating than the center and bottom parts. Therefore, the top part of the high-C as-built alloy retains the $\gamma$-phase. Aging for a sufficient time completely transforms the matrix from the $\gamma$-phase to the $\varepsilon$-phase and ensures that all parts are single $\varepsilon$-phase.

We concluded that the blocky black, white, and gray precipitates observed in the SEM-BSE image are $\mathrm{M}_{23} \mathrm{X}_{6}$-type, $\eta$-phase, and $\pi$-phase, respectively, in our previous study on the Co-28Cr-6Mo-0.23C-0.2N alloy (mass\%, high-C composition) [17].

$\mathrm{Co}_{3} \mathrm{Mo}_{2} \mathrm{Si}$-type, $\sigma$-phase, and $\pi$-phase precipitates are formed in the low-C alloy (see Figure 7), with no $\mathrm{M}_{23} \mathrm{X}_{6}$-type and $\eta$-phase precipitates. According to the results of our previous study, the formation of the $\sigma$-phase is promoted when the carbon content is 0.16 mass $\%$ or less, and the precipitation of the $\mathrm{M}_{23} \mathrm{X}_{6}$-type and $\eta$-phase is suppressed [24-26]. The lack of $\mathrm{M}_{23} \mathrm{X}_{6}$-type and $\eta$-phase precipitates in low-C alloys is considered to be due to their low carbon contents.

TEM examined the precipitates in the low-C as-built alloy. Figure 8 shows bright field (BF) TEM images and selected area diffraction patterns (SADPs) of the blocky white, blocky gray, and needle-shaped black precipitates in the low-C as-built alloy, which are identified as $\mathrm{Co}_{3} \mathrm{Mo}_{2} \mathrm{Si}$-type, $\sigma$-phase, and $\pi$-phase, respectively.
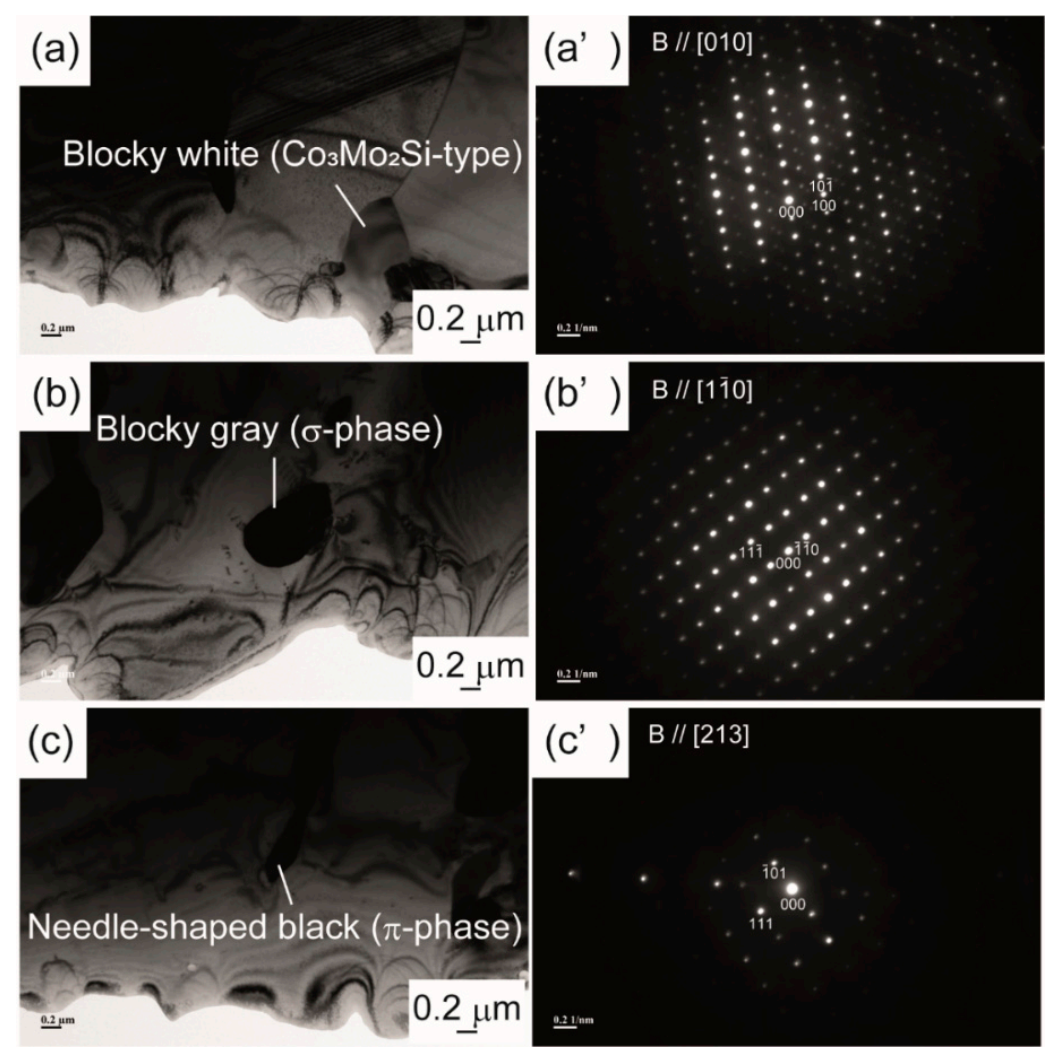

Figure 8. Transmission electron microscopy-bright field (TEM-BF) images and selected area diffraction patterns (SADPs) of the $\left(\mathbf{a}, \mathbf{a}^{\prime}\right)$ blocky white, $\left(\mathbf{b}, \mathbf{b}^{\prime}\right)$ blocky gray, and $\left(\mathbf{c}, \mathbf{c}^{\prime}\right)$ needle-shaped black precipitates of the low-C as-built alloy. 
The chemical compositions of the precipitates in the low-C alloys were quantitatively analyzed by TEM-EDX. Table 2 lists the chemical compositions of the $\mathrm{Co}_{3} \mathrm{Mo}_{2} \mathrm{Si}$-type precipitates in the low-C as-built and reversely transformed alloys. The $\mathrm{Co}_{3} \mathrm{Mo}_{2} \mathrm{Si}$-type precipitate is $\mathrm{Cr}$-poor when compared with the Co-based matrix (Cr: 20 mass\%).

Table 2. Chemical compositions of $\mathrm{Co}_{3} \mathrm{Mo}_{2} \mathrm{Si}$-type precipitates observed in the low-C as-built and reverse treated alloys (analyzed by transmission electron microscopy-energy dispersive X-ray spectrometry (TEM-EDX)).

\begin{tabular}{ccccccccc}
\hline \multirow{2}{*}{ Alloy } & \multicolumn{2}{c}{ Co } & \multicolumn{2}{c}{ Cr } & \multicolumn{2}{c}{ Mo } & \multicolumn{2}{c}{ Si } \\
\cline { 2 - 9 } & mass $\%$ & at $\%$ & mass $\%$ & at $\%$ & mass $\%$ & at $\%$ & mass $\%$ & at $\%$ \\
\hline $\begin{array}{c}\text { as-built } \\
\text { reversely }\end{array}$ & 40.37 & 46.03 & 13.95 & 18.02 & 43.36 & 30.37 & 2.33 & 5.58 \\
transformed & 35.84 & 42.14 & 11.88 & 15.83 & 49.82 & 35.98 & 2.45 & 6.05 \\
\hline
\end{tabular}

Figure 9 summarizes the areal percentages of the precipitates that were calculated from the SEM-BSE images and the phase fractions of the precipitates calculated from the XRD peak intensity ratios. The total amount of precipitates increases after aging, but decreases after the reverse transformation treatment. In the case of the high-C alloys (Figure 9a), the amount of $\mathrm{M}_{23} \mathrm{X}_{6}$-type and $\pi$-phase precipitates increase during aging and decrease during reverse transformation treatment. As shown in Figure $9 b$, in the case of the low-C alloys, the amount of $\pi$-phase precipitates increases slightly after aging, and the $\pi$-phase was completely dissolved by reverse transformation treatment. On the other hand, the amount of $\mathrm{Co}_{3} \mathrm{O}_{2} \mathrm{Si}$-type precipitates was slightly lower after aging, and higher after reverse transformation treatment. These results suggest that the formation and/or dissolution of the precipitates play a role in the $\gamma-\varepsilon$ phase transformation. Section 4.3 discusses the relevant details.
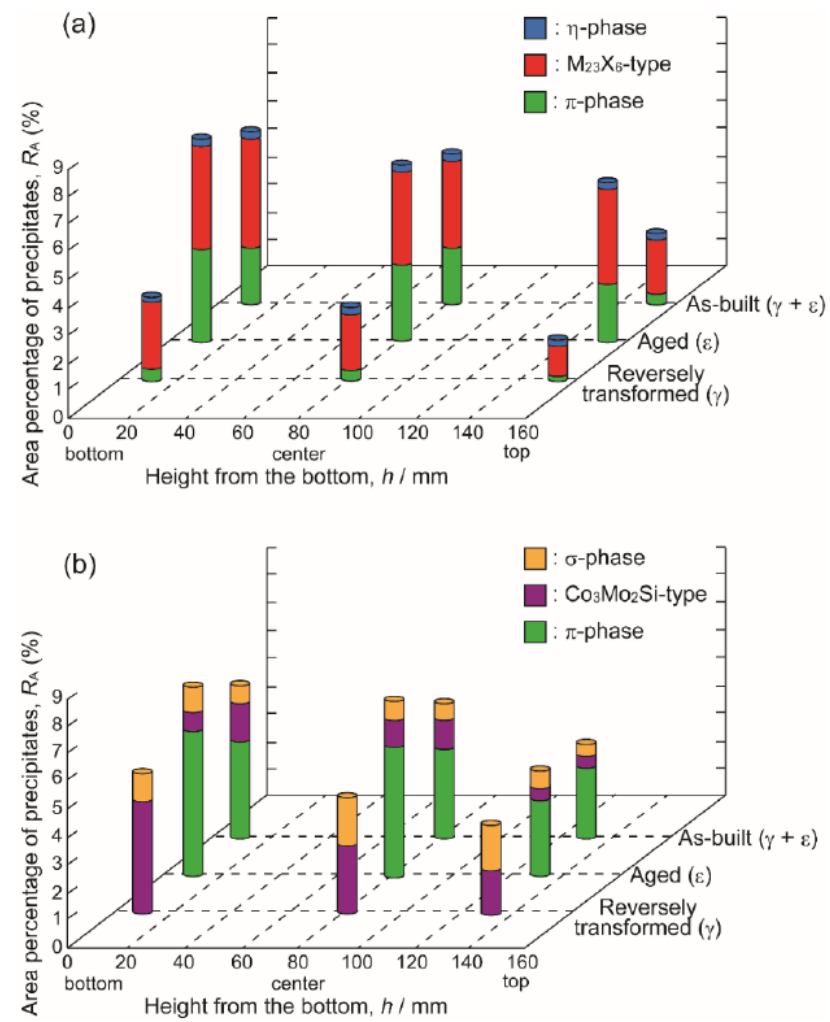

Figure 9. Areal percentages of the precipitates formed in the (a) high-C and (b) low-C alloys. 


\section{2. $\mathrm{Co}_{3} \mathrm{Mo}_{2} \mathrm{Si}$-Type Precipitates}

The $\mathrm{Co}_{3} \mathrm{Mo}_{2} \mathrm{Si}$-type precipitates are called Laves phases and they are represented by the $\mathrm{AB}_{2}$ formula $[28,29]$. Si stabilizes the $\mathrm{MoCo}_{2}$ structure by substituting $\mathrm{Co}$ in the $\mathrm{B}$ site, where other elements, such as $\mathrm{V}, \mathrm{Cr}, \mathrm{Mn}, \mathrm{Fe}, \mathrm{Ni}$, or $\mathrm{Al}$, can be introduced [30]. Therefore, $\mathrm{Mo}(\mathrm{Co}, \mathrm{Cr}, \mathrm{Si})_{2}$ can represent the chemical composition of the $\mathrm{Co}_{3} \mathrm{Mo}_{2} \mathrm{Si}$-type precipitate for a CoCrMo alloy. The formation of $\mathrm{Co}_{3} \mathrm{Mo}_{2} \mathrm{Si}$-type precipitates has been reported in Si-containing $\mathrm{Co}-\mathrm{Cr}$ alloys, such as tribaloy (Co-Mo-Cr-Si alloys) and carbon-free Co-Cr-Mo-W alloy fabricated by powder bed fusion while using direct metal laser sintering technique [31-33]. Liu et al. investigated the effect of alloy composition on the microstructure of a Co-Cr-Mo-Ni alloy and reported the formation of $\mathrm{Co}_{3} \mathrm{Mo}_{2} \mathrm{Si}$-type precipitates when the carbon content was low and the Mo and Si contents were high [32]. However, they did not determine the chemical composition of the $\mathrm{Co}_{3} \mathrm{Mo}_{2} \mathrm{Si}$-type precipitate. Our study is the first to reveal the presence and chemical compositions of $\mathrm{Co}_{3} \mathrm{Mo}_{2} \mathrm{Si}$-type precipitates in biomedical CoCrMo alloys. Santecchia et al. reported that a $\mathrm{Co}_{3}(\mathrm{Mo}, \mathrm{W})_{2} \mathrm{Si}$-type precipitates were formed by performing the heat treatment on the carbon free Co-Cr-Mo-W alloy [33]. The alloy that was used in the study of Santecchia et al. has higher Si content than the CoCrMo alloy that was used in this study. In addition, the CoCrMo alloys that were used in this study contain carbon and do not contain W. We concluded that in the $\mathrm{Co}-\mathrm{Cr}-\mathrm{Mo}$ type alloys, $\mathrm{Co}_{3} \mathrm{Mo}_{2} \mathrm{Si}$-type precipitates are formed when the carbon content is low and $\mathrm{Si}$ content is high by combining the results that were reported by Santecchia et al. [33] and the results of this study. The effect of $\mathrm{W}$ on the precipitation behavior of $\mathrm{Co}_{3} \mathrm{Mo}_{2}$ Si-type precipitates needs to be studied in the future.

\subsection{Effect of $\pi$-Phase and $\mathrm{Co}_{3} \mathrm{Mo}_{2}$ Si-Type Precipitates on $\gamma$-E Transformation during Heat Treatment}

Figure 10 shows EBSD inverse pole figures (IPFs) and phase maps of the middle RT 76, 78, 80, and 90 alloys, the reverse transformation treatments of which were interrupted at 76, 78, 80, and $90 \mathrm{~s}$, respectively. The $\varepsilon$-to- $\gamma$ phase transformation can be observed at $78 \mathrm{~s}$, and the $\gamma$-phase fraction increases with increasing reverse transformation treatment time. In addition, a $\gamma$-phase was formed from both the grain boundary and intragrain regions. The formation of the $\pi$-phase by aging is considered to cause a local decrease in the carbon concentration in the matrix ( $\gamma$-phase). Carbon acts as a $\gamma$-phase stabilizer in CoCrMo alloys [8]. The $\gamma \rightarrow \varepsilon$ phase transformation at the $\pi$-phase/matrix $(\gamma$-phase) interface can be attributed to the decrease in the $\gamma$-phase stability due to $\pi$-phase precipitation. On the other hand, because the $\pi$-phase dissolved during the reverse transformation treatment, carbon diffused around the $\pi$-phase, and the $\gamma$-phase stability increased at the $\pi$-phase/matrix ( $\varepsilon$-phase) interface. We speculate that the formation of new $\gamma$-phase grains originate from the $\pi$-phase/matrix ( $\varepsilon$-phase) interface. $\mathrm{Co}_{3} \mathrm{Mo}_{2} \mathrm{Si}$-type precipitates were formed during the reverse transformation treatment in the low-C alloy. Figure 11 shows the TEM-BF image and SADP of the middle-RT 80 alloy. A new $\gamma$-phase grain is formed from the $\mathrm{Co}_{3} \mathrm{Mo}_{2}$ Si-type precipitate/matrix ( $\varepsilon$-phase) interface. The concentration of Mo, which is known to be a $\varepsilon$-phase stabilizer in CoCrMo alloys [34], locally decreases around the $\mathrm{Co}_{3} \mathrm{Mo}_{2} \mathrm{Si}$-type precipitates, and the $\gamma$-phase of the matrix becomes more stable due to the formation of $\mathrm{Co}_{3} \mathrm{Mo}_{2} \mathrm{Si}$-type precipitates during the reverse transformation treatment. The $\varepsilon \rightarrow \gamma$ phase transformation originates from the $\mathrm{Co}_{3} \mathrm{Mo}_{2} \mathrm{Si}$-type precipitate/matrix ( $\varepsilon$-phase) interface during the reverse transformation treatment. 

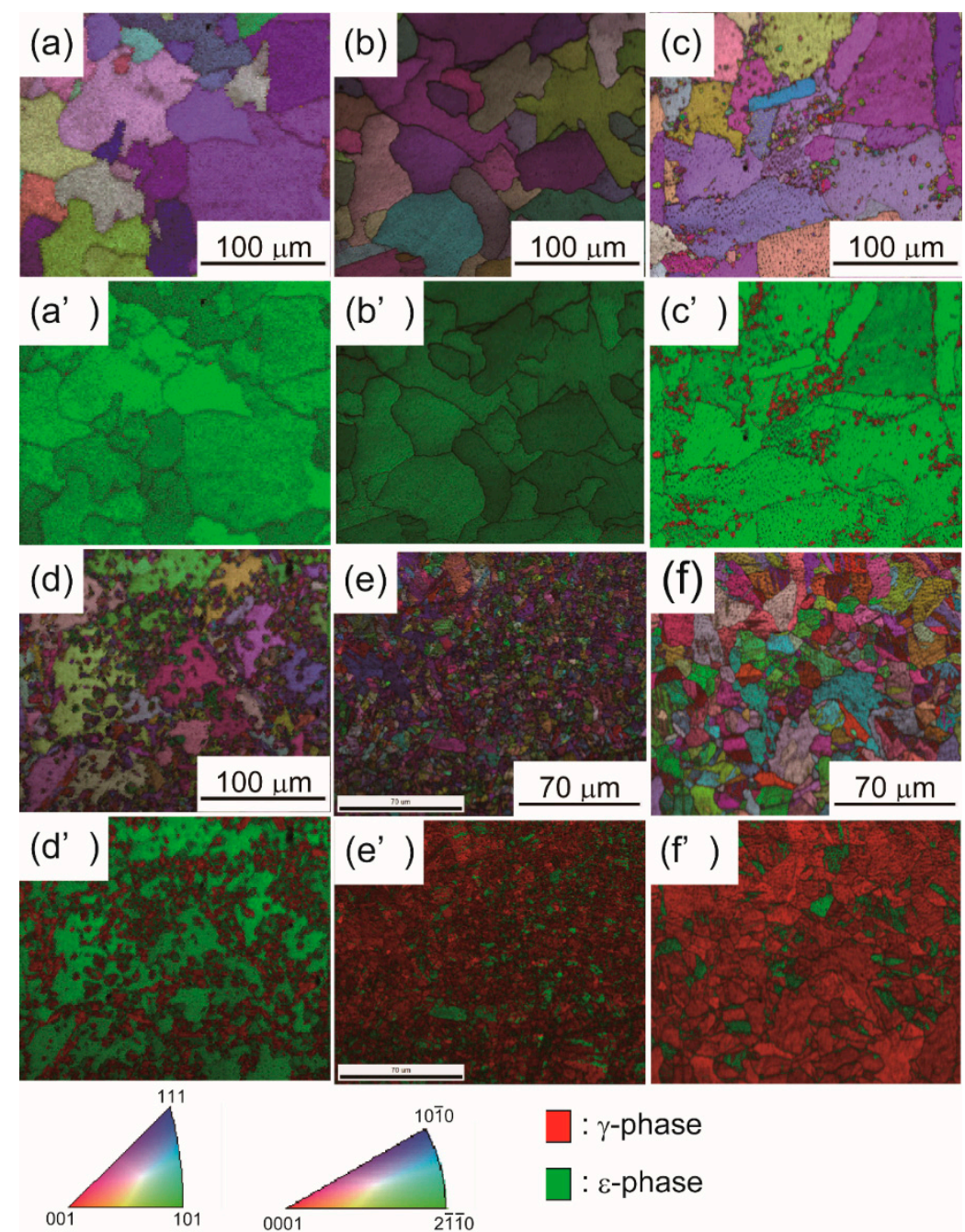

: $\gamma$-phase

: $\varepsilon$-phase

Figure 10. (a-f) electron backscattering diffraction inverse pole figure (EBSD IPF) and $\left(\mathbf{a}^{\prime}-\mathbf{f}^{\prime}\right)$ phase maps of the (a, a') aged, (b, $\left.\mathbf{b}^{\prime}\right)$ middle RT 76, (c, $\left.\mathbf{c}^{\prime}\right)$ middle RT 78, (d, $\left.\mathbf{d}^{\prime}\right)$ middle RT 80, (e, $\left.\mathbf{e}^{\prime}\right)$ middle RT 90 , and $\left(\mathbf{f}, \mathbf{f}^{\prime}\right)$ reversely transformed specimens of the low-C alloy.

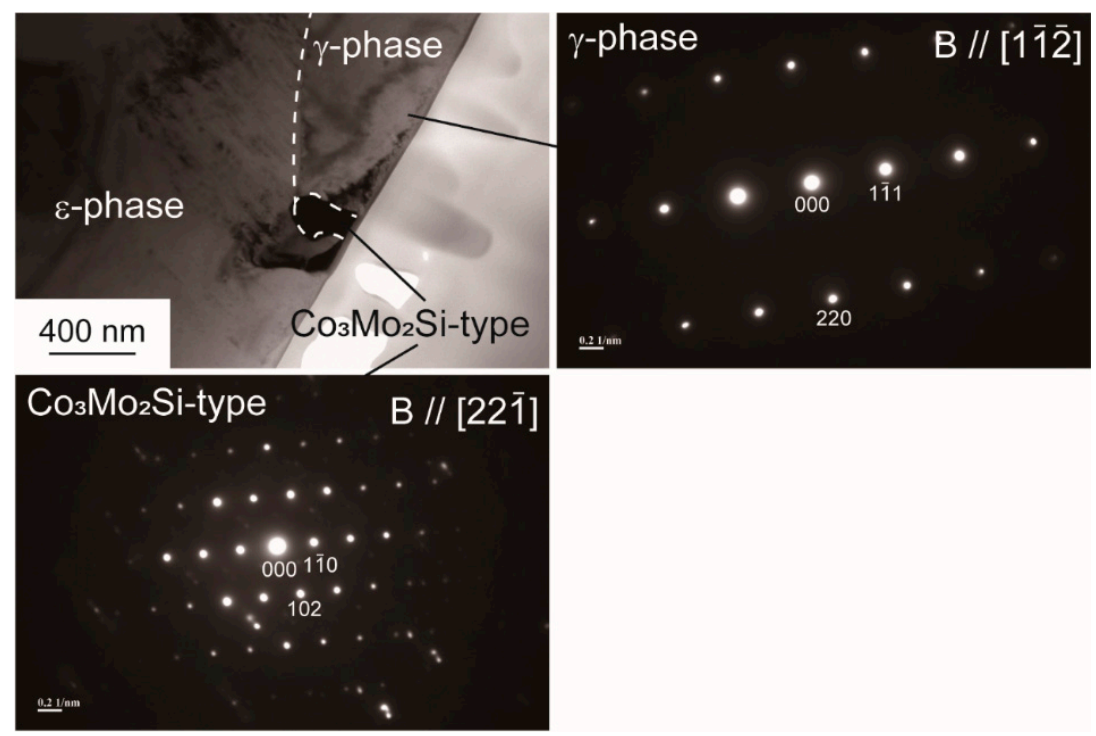

Figure 11. TEM-BF image and SADPs of the $\gamma$-phase and $\mathrm{Co}_{3} \mathrm{Mo}_{2} \mathrm{Si}$-type precipitates that were observed in the middle RT 80 specimen of the low-C alloy. 


\section{Conclusions}

We fabricated Co-Cr-Mo alloys with low and high carbon contents by EBM and studied their precipitation during aging in the $\varepsilon$-phase stability region and their subsequent reverse transformations in the $\gamma$-phase stability region. The following are the main results of this study:

(1) $\mathrm{M}_{23} \mathrm{X}_{6}$-type, $\eta$-phase, and $\pi$-phase precipitates were observed in the high-C alloy, and the $\pi$-phase, $\sigma$-phase, and $\mathrm{Co}_{3} \mathrm{Mo}_{2} \mathrm{Si}$-type precipitates were observed in the low-C alloy.

(2) In the case of the high-C alloy, the amounts of $\mathrm{M}_{23} \mathrm{X}_{6}$-type and $\pi$-phase precipitates increased during aging and decreased during the reverse transformation treatment. In the case of the low-C alloy, the amount of $\pi$-phase precipitates increased slightly during aging, and the $\pi$-phase was completely dissolved by the reverse transformation treatment. The amount of $\mathrm{Co}_{3} \mathrm{Mo}_{2} \mathrm{Si}$-type precipitates slightly decreased during aging and increased during the reverse transformation treatment.

(3) $\mathrm{Co}_{3} \mathrm{Mo}_{2} \mathrm{Si}$-type precipitation in biomedical Co-Cr-Mo alloys was confirmed in this study for the first time, and its chemical composition was revealed, which confirmed that $\mathrm{Cr}$ and Si substituted $\mathrm{Co}$ in the $\mathrm{B}$ site of the $\mathrm{AB}_{2}$ Laves phase structure.

(4) The dissolution of the $\pi$-phase precipitates and the formation of the $\mathrm{Co}_{3} \mathrm{Mo}_{2} \mathrm{Si}$-type precipitates helped to stabilize the $\gamma$-phase during the reverse transformation treatment at the precipitate/matrix ( $\varepsilon$-phase) interface, owing to the increasing carbon content and decreasing Mo content, respectively; therefore, new fine $\gamma$-phase grains were formed at the interface.

Author Contributions: Conceptualization, K.U. (Kosuke Ueki), M.K., K.U. (Kyosuke Ueda), Y.K., D.W., A.C. and T.N.; methodology, K.U. (Kosuke Ueki), M.K., K.U. (Kyosuke Ueda), Y.K. and T.N.; validation, K.U. (Kosuke Ueki), K.U. (Kyosuke Ueda) and T.N.; formal analysis, K.U. (Kosuke Ueki) and M.K.; investigation, K.U. (Kosuke Ueki) and M.K.; resources, Y.K., D.W. and T.N.; data curation, K.U. (Kosuke Ueki), M.K.; writing-original draft preparation, K.U. (Kosuke Ueki); writing—review and editing, T.N.; visualization, K.U. (Kosuke Ueki); supervision, T.N.; project administration, T.N.; funding acquisition, K.U. (Kosuke Ueki), A.C. and T.N. All authors have read and agreed to the published version of the manuscript.

Funding: This study was financially supported by the Japan Society for the Promotion of Science KAKENHI (grant numbers JP 19K23580, 18H01718, 18H03834 and 17H01329).

Acknowledgments: This work was partly supported by the "Creation of Life Innovation Materials for Interdisciplinary and International Researcher Development" project. The authors would like to thank K. Kobayashi of Tohoku University for the TEM analyses.

Conflicts of Interest: The authors declare no conflict of interest.

\section{References}

1. Devine, T.M.; Wulff, J. Cast vs. wrought cobalt-chromium surgical implant alloys. J. Biomed. Mater. Res. 1975, 9, 151-167. [CrossRef] [PubMed]

2. Niinomi, M. Recent metallic materials for biomedical applications. Metall. Mater. Trans. A 2002, 33, 477-486. [CrossRef]

3. Rathee, M.; Bhoria, M.; Boora, P. Oral rehabilitation with metal base complete denture for patient with oral lichen planus. IJRID 2014, 4, 117-122.

4. Buford, A.; Goswami, T. Review of wear mechanisms in hip implants: Paper I-General. Mater. Des. 2004, 25, 385-393. [CrossRef]

5. Vidal, C.V.; Muñoz, A.I. Electrochemical characterization of biomedical alloys for surgical implants in simulated body fluids. Corros. Sci. 2008, 50, 1954-1961. [CrossRef]

6. Koizumi, Y.; Suzuki, S.; Yamanaka, K.; Lee, B.S.; Sato, K.; Li, Y.; Kurosu, S.; Matsumoto, H.; Chiba, A. Strain-induced martensitic transformation near twin boundaries in a biomedical Co-Cr-Mo alloy with negative stacking fault energy. Acta Mater. 2013, 61, 1648-1661. [CrossRef]

7. Lee, S.H.; Nomura, N.; Chiba, A. Significant improvement in mechanical properties of biomedical Co-Cr-Mo alloys with combination of $\mathrm{N}$ addition and Cr-enrichment. Mater. Trans. 2008, 49, 260-264. [CrossRef]

8. Lee, Y.; Yamashita, Y.; Tang, N.; Liu, B.; Kurosu, S.; Matsumoto, H.; Koizumi, Y.; Chiba, A. Influence of carbon and nitrogen addition on microstructure and hot deformation behavior of biomedical $\mathrm{Co}-\mathrm{Cr}-\mathrm{Mo}$ alloy. Mater. Chem. Phys. 2012, 135, 849-854. 
9. Murr, L.E. Metallurgy of additive manufacturing: Examples from electron beam melting. Addit. Manuf. 2015, 5, 40-53. [CrossRef]

10. Takaichi, A.; Nakamoto, T.; Joko, N.; Nomura, N.; Tsutsumi, Y.; Migita, S.; Doi, H.; Kurosu, S.; Chiba, A.; Wakabayashi, N.; et al. Microstructures and mechanical properties of Co-29Cr-6Mo alloy fabricated by selective laser melting process for dental application. J. Mech. Behav. Biomed. Mater. 2013, 21, 67-76. [CrossRef] [PubMed]

11. Sing, S.L.; Huang, S.; Yeong, W.Y. Effect of solution heat treatment on microstructure and mechanical properties of laser powder bed fusion produced cobalt-28chromium-6molybdenum. Mater. Sci. Eng. A 2020, 769, 138511. [CrossRef]

12. Wei, D.; Koizumi, Y.; Takashima, T.; Nagasako, M.; Chiba, A. Fatigue improvement of electron beam melting-fabricated biomedical Co-Cr-Mo alloy by accessible heat treatment. Mater. Res. Lett. 2018, 6, 93-99. [CrossRef]

13. Murr, L.E.; Gaytan, S.M.; Medina, F.; Martinez, E.; Martinez, J.L.; Hernandez, D.H.; Machado, B.I.; Ramirez, D.A.; Wicker, R.B. Characterization of Ti-6Al-4V open cellular foams fabricated by additive manufacturing using electron beam melting. Mater. Sci. Eng. A 2010, 527, 1861-1868. [CrossRef]

14. Ramirez, D.A.; Murr, L.E.; Li, S.J.; Tian, Y.X.; Martinez, E.; Martinez, J.L.; Machado, B.I.; Gaytan, S.M.; Medina, F.; Wicker, R.B. Open-cellular copper structures fabricated by additive manufacturing using electron beam melting. Mater. Sci. Eng. A 2011, 528, 5379-5386. [CrossRef]

15. Sun, S.H.; Koizumi, Y.; Kurosu, S.; Li, Y.P.; Chiba, A. Phase and grain size inhomogeneity and their influence on creep behavior of Co-Cr-Mo alloy additive manufactured by electron beam melting. Acta Mater. 2015, 86, 305-318. [CrossRef]

16. López, H.F.; Saldivar-Garcia, A.J. Martensitic transformation in a cast Co-Cr-Mo-C alloy. Metall. Mater. Trans. A 2008, 39, 8-18. [CrossRef]

17. Wei, D.; Koizumi, Y.; Chiba, A.; Ueki, K.; Ueda, K.; Narushima, T.; Tsutsumi, T.; Hanawa, T. Heterogeneous microstructures and corrosion resistance of biomedical Co-Cr-Mo alloy fabricated by electron beam melting (EBM). Addit. Manuf. 2018, 24, 103-114. [CrossRef]

18. Sun, S.H.; Koizumi, Y.; Kurosu, S.; Li, Y.P.; Matsumoto, H.; Chiba, A. Build direction dependence of microstructure and high-temperature tensile property of $\mathrm{Co}-\mathrm{Cr}-\mathrm{Mo}$ alloy fabricated by electron beam melting. Acta Mater. 2014, 64, 154-168. [CrossRef]

19. Wei, D.; Anniyaer, A.; Koizumi, Y.; Aoyagi, K.; Nagasako, M.; Kato, H.; Chiba, A. On microstructural homogenization and mechanical properties optimization of biomedical Co-Cr-Mo alloy additively manufactured by using electron beam melting. Addit. Manuf. 2019, 28, 215-227. [CrossRef]

20. Kurosu, S.; Matsumoto, H.; Chiba, A. Grain refinement of biomedical Co-27Cr-5Mo-0.16 N alloy by reverse transformation. Mater. Lett. 2010, 64, 49-52. [CrossRef]

21. Mori, M.; Yamanaka, K.; Chiba, A. Phase decomposition in biomedical Co-29Cr-6Mo-0.2 N alloy during isothermal heat treatment at $1073 \mathrm{~K}$. J. Alloys Compd. 2014, 590, 411-416. [CrossRef]

22. Kurosu, S.; Matsumoto, H.; Chiba, A. Isothermal phase transformation in biomedical Co-29Cr-6Mo alloy without addition of carbon or nitrogen. Metall. Mater. Trans. A 2010, 41, 2613-2625. [CrossRef]

23. Mineta, S.; Namba, S.; Yoneda, T.; Ueda, K.; Narushima, T. Precipitates in as-cast and heat-treated ASTM F75 Co-Cr-Mo alloys containing Si and/or Mn. Metall. Mater. Trans. A 2011, 42, 1941-1949.

24. Mineta, S.; Namba, S.; Yoneda, T.; Ueda, K.; Narushima, T. Precipitates in biomedical Co-28Cr-6Mo-(0-0.41) C alloys heat-treated at $1473 \mathrm{~K}$ to $1623 \mathrm{~K}\left(1200{ }^{\circ} \mathrm{C}\right.$ to $\left.1350{ }^{\circ} \mathrm{C}\right)$. Metall. Mater. Trans. A 2012, 43, 3351-3358. [CrossRef]

25. Mineta, S.; Namba, S.; Yoneda, T.; Ueda, K.; Narushima, T. Carbide formation and dissolution in biomedical Co-Cr-Mo alloys with different carbon contents during solution treatment. Metall. Mater. Trans. A 2010, 41, 2129-2138. [CrossRef]

26. Narushima, T.; Mineta, S.; Kurihara, Y.; Ueda, K. Precipitates in biomedical Co-Cr alloys. JOM 2013, 65, 489-504. [CrossRef]

27. Narushima, T.; Mineta, S.; Namba, S.; Yoneda, T.; Ueda, K. Precipitates in biomedical Co-Cr-Mo-C-Si-Mn alloys. Adv. Mater. Res. 2011, 277, 51-58. [CrossRef]

28. Ueki, K.; Kurihara, Y.; Mineta, S.; Ueda, K.; Namba, S.; Yoneda, T.; Narushima, T. Changes in microstructure of biomedical Co-Cr-Mo alloys during aging at 973 to 1373 K. Mater. Trans. 2016, 57, 2048-2053. [CrossRef] 
29. Liu, Y.; Wang, H.M. Elevated temperature wear behaviors of a Co-Mo-Si ternary metal silicide alloy. Scrip. Materialia 2005, 52, 1235-1240. [CrossRef]

30. Bardos, D.I.; Gupta, K.P.; Beck, P.A. Ternary laves phases with transition elements and silicon. Trans. Metall. Soc. AIME 1961, 221, 1087-1088.

31. Liu, R.; Yao, M.X.; Patnaik, P.C.; Wu, X. Effects of heat treatment on mechanical and tribological properties of cobalt-base tribaloy alloys. J. Mater. Eng. Perform. 2005, 14, 634-640. [CrossRef]

32. Liu, R.; Xi, S.Q.; Kapoor, S.; Wu, X.J. Effects of chemical composition on solidification, microstructure and hardness of Co-Cr-W-Ni and Co-Cr-Mo-Ni alloy systems. Int. J. Res. Rev. Appl. Sci. 2010, 5, 110-122.

33. Santecchia, E.; Gatto, A.; Bassoli, E.; Denti, L.; Rutkowski, B.; Mengucci, P. Precipitates formation and evolution in a Co-based alloy produced by pwder bed fusion. J. Alloy. Compd. 2019, 797, 652-658. [CrossRef]

34. Achmad, T.L.; Fu, W.; Chen, H.; Zhang, C.; Yang, Z.G. First-principles calculations of generalized-stacking-fault-energy of Co-based alloys. Comp. Mater. Sci. 2016, 121, 86-96. [CrossRef]

(C) 2020 by the authors. Licensee MDPI, Basel, Switzerland. This article is an open access article distributed under the terms and conditions of the Creative Commons Attribution (CC BY) license (http://creativecommons.org/licenses/by/4.0/). 